\title{
ПРЕДИКТОРЫ ФОРМИРОВАНИЯ ФАРМАКОРЕЗИСТЕНТНОСТИ ПРИ ЭПИЛЕПСИИ
}

\author{
Г.А.Дущанова, *Э.Т. Зулфикарова \\ Южно-Казахстанская государственная фармацевтическая академия, г.Шымкент, Казахстан
}

Эпилепсия - заболевание, требующее длительной терапии. При установлении фармакорезистентности необходимо точное выявление возможных причин, т.к. зачастую неэффективность фармакотерапии у больных эпилепсией является результатом неверно подобранного неадекватного антиэпилептического лечения, что значительно ухудшает прогноз. В исследование включено 89 больных в возрасте от 17 до 55 лет, направленных с предположительным диагнозом- фармакорезистентность.

Таким образом, анализируя предшествующую терапию у больных с предполагаемой фармакорезистентностью, нами выявлено, что в подавляющем большинстве речь может идти о относительной резистентности, которая связана с: неправильной диагностикой эпилепсии, неудачным подбором, дозировки и тактики (в ряде случаев необходимости титрования) назначения препарата, неоправданным использованием политерапии и как следствие этого выраженными побочными эффектами лекарственных препаратов, нарушением регулярности приема препаратов низкой комплаентности с врачом неврологом.

7 пилепсия - заболевание, требующее дли-
тельной, многолетней, (не менее 2 лет после прекращения приступов) терапии. Эта терапия имеет принципиальное значение для здоровья больного, качества жизни; ее эффект в большинстве случаев очевиден.

Пациенты с устойчивыми к лечению формами эпилепсии - это наиболее важная и трудная проблема, с которой сталкиваются врачи - неврологи и представляют диспропорционально большую группу среди всех больных эпилепсией. Даже после оптимального назначения известных антиэпилептических препаратов, у 10-30\% больных эпилепсией, по данным различных авторов, сохраняются эпилептические приступы.

В контингенте больных значительная доля потенциально трудоспособных молодых людей, для которых применение нетоксичного высокоэффективного препарата в течение нескольких лет с прогнозируемым выздоровлением, может явиться разумной альтернативой пожизненной инвалидности. При установлении фармакорезистентности у больных эпилепсией необходимо точное выявление возможных причин, т.к. зачастую неэффективность фармакотерапии у больных эпилепсией является результатом неверно подобранного неадекватного антиэпилептического лечения, что значительно ухудшает прогноз. Целью лечения эпилепсии является предотвращение развития приступов с применением антиэпи- лептических препаратов (АЭП) и обеспечением постоянной адекватной их концентрации в крови.

Фармакорезистентность - это невозможность достичь полного или почти полного контроля над припадками при помощи адекватно подобранных противоэпилептических средств. По данным ВОЗ (2008), подавляющее большинство больных эпилепсией не получает адекватного лечения, вследствие чего, в большинстве случаев, формируется фармакорезистентность к АЭП 1 и 2 очереди выбора

Фармакорезистентность считается установленной, если у пациента были применены препараты первого ряда (карбамазепин, вальпроаты) в монотерапии и в комбинации, в максимально переносимых дозах и с приемлемыми для пациента пробочными эффектами, несмотря на плазменные уровни АЭП. Однако, по международным понятиям, фармакорезистентность может быть установлена только после применения одного или нескольких "новых АЭП".

$\mathrm{C}$ целью выявления факторов влияющих на развитие резистентности при идиопатической эпилепсии нами проведено исследование в соответствии с международными стандартами.

Из 892 больных эпилепсией, наблюдавшихся нами в течение 2-х лет, в исследование включено 89 больных в возрасте от 17 до 55 лет, направленных с предположительным ди-

*e-mail: ellichka.zh@mail.ru 
агнозом - фармакорезистентность.

На первом этапе нашего исследования проводился анализ проводившегося лечения: все они $(100 \%)$ получали неадекватную противоэпилептическую терапию:

- 93,4\% больных получали некорректную политерапию

- 6,6\% - получали некорректную монотерапию

- 12,3\% - получали сначала некорректную (неадекватную) монотерапию, а затем некорректную политерапию.

Большинство больных получали фенобарбитал и его производные, карбамазепин и вальпроаты в неадекватно низкой дозе.

Продолжительность приема антиэпилептической терапии колебалась от полугода до 3-6 лет. Средняя продолжительность составила $3,71 \pm 5,46$ года

Причины неэффективности антиэпилептической терапии:

1. неадекватная терапия

2. побочные эффекты антиэпилептических препаратов, как следствие неоправданной политерапии.

На втором этапе нашего исследования проводилась коррекция антиэпилептической терапии у пациентов, получавших ранее неадекватное лечение.

В результате подбора антиэпилептической терапии удалось:

- добиться ремиссии у 7,9\% больных,

- урежение частоты приступов зарегистрировано у $70,7 \%$ больных,

- у 21,3\% пациентов не было эффекта, несмотря на проводимую терапию.

У выявленных нами больных с фармакорезистентной эпилепсией ведущим этиологическим фактором была:

- перинатальная патология (гипоксия, родовая травма),
- перенесенные нейроинфекции,

- постнатальные черепно-мозговые травмы, часто повторные, неблагоприятная наследственность

Таким образом, анализируя предшествующую терапию у больных с предполагаемой фармакорезистентностью, нами выявлено, что в подавляющем большинстве речь может идти о относительной резистентности, которая связана с:

- неправильной диагностикой эпилепсии,

- неудачным подбором, дозировки и тактики (в ряде случаев необходимости титрования) назначения препарата,

- неоправданным использованием политерапии и как следствие этого выраженными побочными эффектами лекарственных препаратов,

- нарушением регулярности приема препаратов

- низкой комплаентности с врачом неврологом.

Несмотря на то, что первоначально больные были направлены с подозрением на фармакорезистентность эпилепсии, в результате уточнения клинического диагноза, индивидуализированного подхода к выбору и дозам АЭП в зависимости от формы эпилепсии, типа приступов и индивидуальных показателей (возраст, масса тела и т.д.), нами показано, что число случаев истинной фармакорезистентности $21,3 \%$.

\section{Выводы:}

1. Установление фармакорезистентности в соответствии с международным определением в наиболее ранние сроки от начала заболевания улучшает прогноз течения заболевания у больных с эпилепсией.

2.Индивидуализированный подход к лечению позволяет значительно снизить фармакорезистентность при эпилепсии. 


\title{
SUMMARY
}

\section{PREDICTORS PHARMACORESISTANCE FORM OF EPILEPSY}

\author{
G.A.Duschanova, E.T.Zulfikarova
}

South Kazakhstan State Pharmaceutical Academy, Shymkent, Kazakhstan

Epilepsy - a disease that requires long-term therapy. In establishing pharmacoresistance need precise identification of possible reasons, because often ineffective drug therapy in patients with epilepsy is the result of incorrectly matched inadequate antiepileptic treatment, significantly worsens the prognosis. The study included 89 patients aged 17 to 55 years, referred with a presumptive diagnosis-drug-resistant.

Thus, by analyzing previous therapy in patients with suspected drug resistant, we found that the vast majority of it could be a relative resistance, which is associated with: a misdiagnosis of epilepsy, bad selection, dosage and tactics (in some cases the need titration) administration of the drug, unjustified use of polytherapy and as a consequence, significant sideeffects of drugs, a violation of the regularity of the drugs low compliance with the neurologist. 